\title{
A 4-year study on clinical characteristics of children hospitalized with rotavirus gastroenteritis
}

\author{
Stefanie Wildi-Runge • Simone Allemann • \\ Urs B. Schaad • Ulrich Heininger
}

Received: 19 November 2008 / Accepted: 24 January 2009 /Published online: 11 February 2009

(C) Springer-Verlag 2009

\begin{abstract}
Rotavirus (RV) is a frequent cause of severe gastroenteritis (GE) in children. With the licensure of new $\mathrm{RV}$ vaccines, data on the burden of disease are important regarding immunization strategies. We reviewed the medical records of children hospitalized with RV infection in our institution between July 2002 and March 2006. Relevant data were extracted in a standardized fashion from records of hospitalized children with a positive RV antigen test in a stool sample. Severity of disease was graded by the 20-point Vesikari score. Population data were obtained from the Federal Office of Statistics. Six hundred eighty-six RVGE were identified and records of 608 hospitalizations (in 607 children) were available. In 539 $(89 \%)$ cases, RVGE was the primary reason for hospitalization and 69 (11\%) were nosocomial infections; yearly peaks occurred between February and May. Cumulative incidence of RVGE was 26.7/1,000 children $<3$ years of age. Median age of 539 children $(55.6 \%$ male) with primary RVGE was 1.4 years and median stay in the hospital for both community acquired and nosocomial RVGE was 4 days (interquartile range 3-5). Thirtypercent and $94 \%$ of RV hospitalizations were in children $<1$ and $<3$ years of age, respectively. Mean Vesikari score was 15 (range 6-20; 96\% >11). Intravenous fluids were administered in $378(70 \%)$ patients, $130(24 \%)$ patients were rehydrated via nasogastral tube, and $31(5.7 \%)$ received rehydration by mouth. RVGE causes a substantial burden in children with an estimated risk for hospitalization due to RVGE of one in 37 children $<3$ years of age.
\end{abstract}

Keywords Rotavirus $(\mathrm{RV}) \cdot$ Children $\cdot$ Vaccine

S. Wildi-Runge $\cdot$ S. Allemann $\cdot$ U. B. Schaad $\cdot$ U. Heininger $(\bowtie)$

University Children's Hospital (UKBB),

P.O. Box, 4005 Basel, Switzerland

e-mail: Ulrich.Heininger@ukbb.ch

\section{Introduction}

Diarrhea remains one of the most important global public health challenges [17]. Human rotavirus (RV), an important causative agent of severe gastroenteritis in infants and young children worldwide, leads to high morbidity in both developing and developed countries and high mortality in developing countries. In developing countries, approximately 440,000 deaths are caused by RV each year. A model developed by the Centers for Disease Control and Prevention (CDC) to evaluate the global burden of RV disease estimated that more than 220,000 hospitalizations and 1.7 million out-patient visits were attributable to RV each year in industrialized countries, including Europe, USA, Japan, and Australia. A further seven million cases of RV infections were managed entirely at home [23].

In developed countries, the disease usually is mild and rarely leads to death. Nevertheless, RV has a major impact on the quality of life of infected infants and children, their parents, and families [14].

Studies of the disease burden of RV conducted in Europe and the USA have included retrospective studies of diarrheal hospitalization [8, 13, 28], laboratory-based studies $[28,30]$, reviews of published and unpublished data [18, 25], and analyses of cost effectiveness [29]. Data about RV morbidity in Europe are available mainly for southern [2, 9, 26], northern [16, 31], and western parts [1, 3, 6, 11, 28]. Only a few studies were performed in eastern Europe [22]. In most countries, detection of RV is not notifiable, and disease estimates are frequently based on laboratory data or hospital discharge data. Of note, the incidence of community-acquired RV infections remains unknown and that of nosocomial RV infections might be underestimated in studies based solely on hospital discharge data.

Examples of rates of hospitalization for RV infection in children $<5$ years of age are one in 40 in the UK [28], one 
in 33 in Finland [33], one in 73 in the general US population [13], one in 100 in Germany [10], and one in 132 in the region of Berne, Switzerland [6].

RV vaccines have been developed to reduce the morbidity associated with severe RV diarrhea. A live oral vaccine was introduced in the USA in $1998[15,25]$ but was withdrawn soon thereafter because of its association with intussusceptions [7]. Today, two new live-attenuated, oral vaccines are available for use in young infants, up to 6 months of age, in many countries: a pentavalent bovinederived RV vaccine and a monovalent human-derived RV vaccine [4, 32]. With the recent licensure of these new vaccines, local data on the current burden of RV disease are important for decisions regarding immunization strategies [34]. To obtain such data, we reviewed the medical records of all children hospitalized in our institution (which provides primary, secondary, and tertiary care for the population in Northwestern Switzerland) with laboratory confirmed RV infection between January 2002 and March 2006.

\section{Materials and methods}

Patients were identified from two data sources: (1) laboratory log books for rotavirus antigen testing (Diarlex ${ }^{\circledR}$ Rota, Orion Diagnostica, Finland) and (2) the hospital inpatient data base (ICD-10-Code "A 08.0 Rotavirus Enteritis"). Relevant data (e.g., age, gestational age, gender, signs and symptoms of infection, treatment) were extracted in a standardized fashion from records of all patients with a positive RV antigen test in a stool sample hospitalized between January 2002 and March 2006. Severity of disease was graded with the use of the 20-point Vesikari score [27]. Annual incidence of hospitalization was calculated based on population data obtained from the Federal Office of Statistics [5].

On a routine basis, stool specimens were collected from all children hospitalized due to gastroenteritis or with new onset of gastroenteritis during hospitalization and tested for RV with an enzyme immunoassay (Diarlex ${ }^{\circledR}$ Rota, Orion Diagnostica).

Primary RV gastroenteritis was defined as cases where gastroenteritis was the leading cause for hospitalization. When onset of gastroenteritis occurred during hospitalization, possible nosocomial infection was assumed if this occurred $24-48 \mathrm{~h}$ after hospitalization and definite nosocomial infection was assumed if this occurred $>48 \mathrm{~h}$ after hospitalization.

We used SPSS Software 13.0 for Windows for statistical analyses. Differences between proportions were assessed by the chi-square test. The adopted level of significance was $<0.05$. The study was approved by the University's Ethics Committee.
Fig. 1 Seasonal distribution of RV infections by month (July to June) and study year
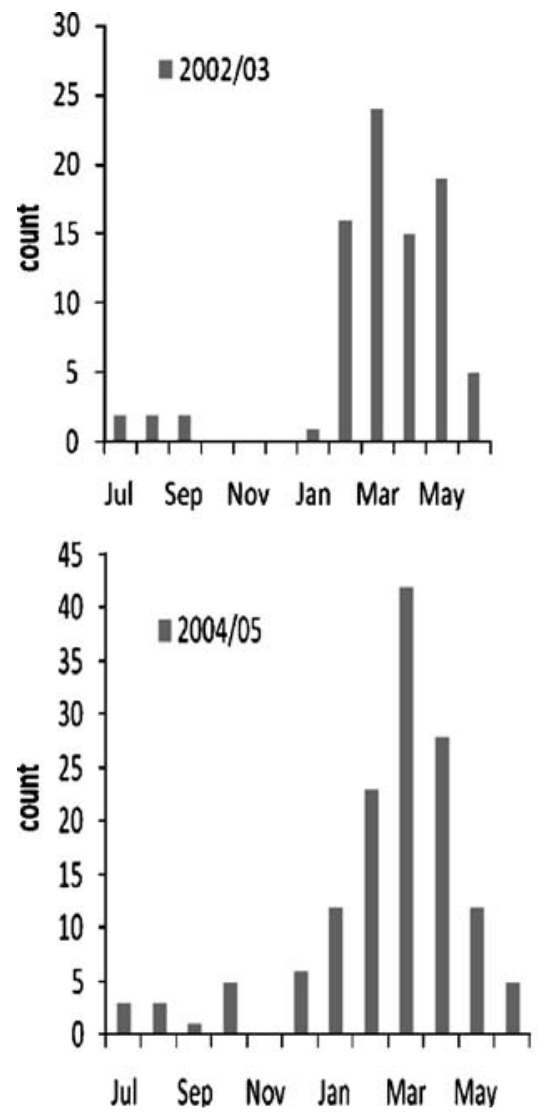
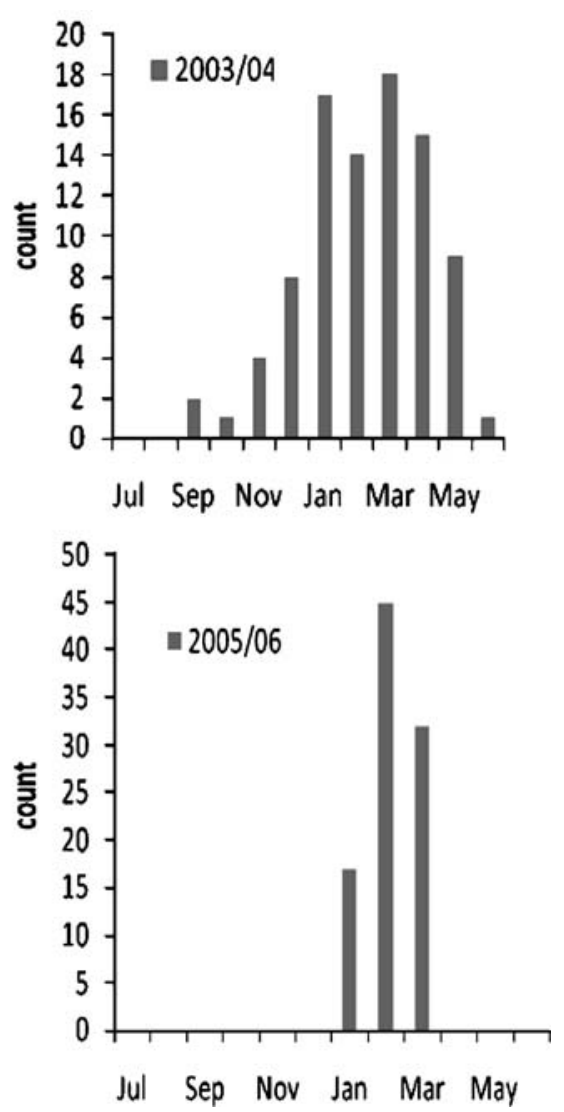


\section{Results}

General characteristics

A total of 686 cases were identified and records of 608 hospitalizations (in 607 children) were available for analysis. Of these, 539 (88.7\%) were community acquired, $21(3.5 \%)$ were possible and $30(4.9 \%)$ were definite nosocomial infections. In the remaining 18 cases, documentation was insufficient for classification.

The mean age of patients with primary RV gastroenteritis $(55.6 \%$ male) was 1.4 years and the cumulative incidence of RV hospitalizations was 26.7/1,000 children under 3 years of age. RV gastroenteritis had a strong seasonality with yearly peaks between February and May (Fig. 1). The median stay in hospital was 4 days (interquartile range 3-5) for both community acquired and nosocomial RV gastroenteritis. Of RV hospitalizations, $30 \%$ and $94 \%$ were in children under 1 and under 3 years of age, respectively.

There were proportionally more children with foreign nationality hospitalized with primary $\mathrm{RV}$ gastroenteritis (46.4\%) when compared to all children living in the cantons of Basel (32.3\%).
Clinical characteristics

Relevant clinical characteristics for primary and nosocomial RV gastroenteritis are demonstrated in Table 1. Of 539 patients with primary RV gastroenteritis, 127 (23.6\%) had persistent diarrhea for more than 5 days and 272 (50.5\%) had concomitant vomiting for $>2$ days. A body temperature $\geq 39^{\circ} \mathrm{C}$ was documented in $252(46.8 \%)$ patients. Dehydration ( $>5 \%$ loss of body weight) was observed in 461 $(85.5 \%)$ patients. Patients without dehydration were hospitalized due to feeding difficulties. Severity of disease was less pronounced in nosocomial infections with lower percentages of patients with vomiting for $>2$ days and dehydration $\geq 5 \%$ (Table 1 ).

Hundred and four (19.3\%) of 539 patients with primary RV gastroenteritis had concomitant signs or symptoms of upper airway infections including 39 patients (7.2\%) with an acute otitis media; further, $11(2 \%)$ patients presented with bronchitis.

Seventy (13.0\%) of 539 patients hospitalized with primary RV gastroenteritis had underlying chronic diseases and one of them died during hospitalization. This was a 13-month-old boy with autoimmune hemolytic anemia and

Table 1 Comparison of clinical characteristics of community acquired versus nosocomial RV gastroenteritis

\begin{tabular}{|c|c|c|c|c|}
\hline Signs and symptoms & $\begin{array}{l}\text { Community acquired }(N=539) \\
N / N \text { known }(\%)\end{array}$ & $\begin{array}{l}\text { Nosocomial }(N=51) \\
N / N \text { known }(\%)\end{array}$ & Odds ratio $(95 \% \mathrm{CI})$ & $p$ value \\
\hline \multicolumn{5}{|l|}{ Any vomiting (days) } \\
\hline 1 & $134 / 519(24.9)$ & $8 / 39(16.0)$ & & \\
\hline 2 & $113 / 519(21.0)$ & $8 / 39(16.0)$ & & \\
\hline$>2$ & $272 / 519(50.5)$ & $23 / 39(45.0)$ & $0.8(0.7-1.2)$ & 0.63 \\
\hline \multicolumn{5}{|c|}{ Vomiting: frequency/day (maximum) } \\
\hline 1 & $38 / 519(7.1)$ & $7 / 39(14.0)$ & & \\
\hline 2 & $56 / 519(10.4)$ & $14 / 39(28.0)$ & & \\
\hline$>2$ & $425 / 519(78.8)$ & $18 / 39(35.0)$ & $5.3(2.6-10.8)$ & 0.001 \\
\hline \multicolumn{5}{|l|}{ Any diarrhea (days) } \\
\hline $1-4$ & $318 / 530(59.0)$ & $33 / 47(65.0)$ & & \\
\hline 5 & $85 / 530(15.8)$ & $5 / 47(10.0)$ & & \\
\hline$>5$ & $127 / 530(23.6)$ & $9 / 47(18.0)$ & $1.3(0.6-3.0)$ & 0.46 \\
\hline \multicolumn{5}{|c|}{ Diarrhea: frequency/day (maximum) } \\
\hline $1-3$ & $174 / 531(32.2)$ & $24 / 47(47.0)$ & & \\
\hline $4-5$ & $166 / 531(30.8)$ & $12 / 47(24.0)$ & & \\
\hline$>5$ & $191 / 531(35.4)$ & $11 / 47(22.0)$ & $1.8(0.9-3.9)$ & 0.08 \\
\hline \multicolumn{5}{|l|}{ Body temperature $\left({ }^{\circ} \mathrm{C}\right)$} \\
\hline $37.1-38.4$ & $202 / 536(37.5)$ & $13 / 47(26.0)$ & & \\
\hline $38.5-38.9$ & $79 / 536(14.7)$ & $11 / 47(22.0)$ & & \\
\hline$\geq 39$ & $252 / 536(46.8)$ & $23 / 47(45.0)$ & $0.9(0.5-1.8)$ & 0.80 \\
\hline \multicolumn{5}{|l|}{ Dehydration (\%) } \\
\hline No & $38 / 538(7.1)$ & $28 / 49(55.0)$ & & \\
\hline$<5 \%$ & $39 / 538(7.2)$ & $4 / 49(8.0)$ & & \\
\hline$\geq 5 \%$ & $461 / 538(85.5)$ & $17 / 49(33.0)$ & $11.3(5.7-22.4)$ & $<0.001$ \\
\hline
\end{tabular}


thrombocytopenia who died from cardiac shock due to intractable gastrointestinal bleeding in association with RV gastroenteritis.

The mean Vesikari score in patients with primary RV gastroenteritis was 15.3 (range 6-20) and 519 (96.3\%) patients had a score $\geq 11$, generally considered as "severe disease" (Fig. 2). In patients with possible and definite nosocomial infections, mean Vesikari scores were 13.1 and 11.7, respectively (differences not significant).

The mean Vesikari score in patients with underlying diseases and primary healthy patients were similar (15.1 versus 15.0 ) and the mean duration of hospitalization was identical (4.7 days). Forty (98.0\%) of 41 pre-term infants and $411(96.5 \%)$ of 426 full-term infants with primary RV gastroenteritis had Vesikari scores $>11 \quad(p=0.89)$.

\section{Treatment of RV gastroenteritis}

Of 539 patients with primary RV gastroenteritis, 378 (70.1\%) required i.v. fluids, $130(24.1 \%)$ were orally rehydrated via a nasogastral tube, and $31(5.7 \%)$ received oral rehydration. Only three patients required intensive care treatment.

Laboratory results

Among patients with primary RV gastroenteritis, 84.8\% (457 of 534) had signs of acidosis in a capillary blood gas analysis

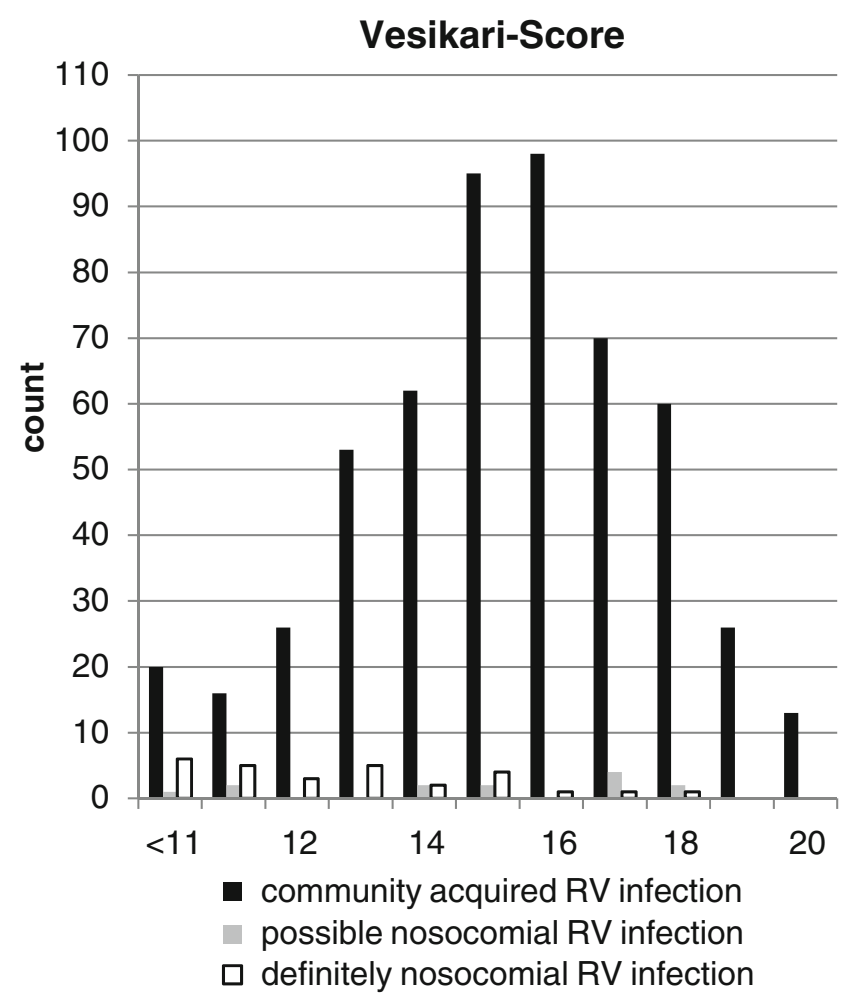

Fig. 2 Vesikari scores in patients with primary RV gastroenteritis (i.e., base excess $<-5$ and/or $\mathrm{pH}<7.35$ ) on admission. The white blood cell account revealed leukocytosis $(\geq 15,000$ leukocytes $/ \mu 1)$ in $14.8 \%$ (80 of 431$)$ patients and CRP was elevated ( $>5 \mathrm{mg} / \mathrm{l})$ in $36.9 \%$ (199 of 424) patients.

\section{Discussion}

Each year, RV causes approximately 111 million episodes of gastroenteritis worldwide with a peak between 6 months to 2 years of age, 25 million clinic visits, two million hospitalizations, and 352,000-592,000 deaths. By the age of 5 years, almost every child has had one or more episodes of RV gastroenteritis of which one in five led to a clinic visit, one in 65 to hospitalization, and approximately one in 293 to death [23].

In the present study, $94 \%$ of hospitalizations due to RV gastroenteritis occurred in children $<3$ years with a cumulative incidence of 26.7/1,000 children in this age group. This is in the range of similar previous investigations in various other countries (11.1 to $36 / 1,000)[20,21,28]$. When compared to the recent study in the region of Berne, where one in 132 children $<5$ years of age was hospitalized because of RV gastroenteritis, our proportion (one in 37 children $<3$ years of age) was higher [6]. This variability may be explained by differences in study designs and periods, living conditions, and social behaviors. Several observations indicate that RV-coded discharges likely capture only a fraction of all RV hospitalizations [21, 28]. Our study design, where all laboratory tests for RV infection were screened, makes it unlikely that a significant number of cases have been missed.

As expected, median age of our patients was low (1.4 years) and $30 \%$ of cases occurred in infants. This reflects the known epidemiology of RV gastroenteritis and is also in agreement with a previous study from members of our group in the ambulatory sector, where the mean age of patients with RV gastroenteritis was 1.5 years [19]. Similarly, Velazquez et al. showed that the incidence of any type of rotavirus infection is generally highest among infants 6-14 months old and decreases in children 2123 months old. They also reported a high incidence of reinfection which, however, usually is mild [30]. Accordingly, only one of 607 children in our case series was hospitalized twice for RV gastroenteritis.

Complications caused by RV infection were rare and no deaths causally related to RV infection occurred, although one child with underlying disease died while suffering from nosocomial RV gastroenteritis.

In Europe, yearly RV seasons start in Spain during December and progresses towards the northeast, reaching The Netherlands and Finland by March [23]. Accordingly, we observed yearly peaks between February and May. 
RV gastroenteritis is associated with a significant burden for patients and parents, medical staff, and society [14, 21]. The associated costs of any disease are very dependent on the seriousness of the illness, but also on the level of patient's dependence. It is important to underline that the main burden of hospitalization due to RV gastroenteritis is with children under 2 years of age [11, 12, 20, 24].

Approximately $10 \%$ of RV infections were nosocomial and these cases tended to be less severe than those acquired in the community. This is not surprising as only a minority of $\mathrm{RV}$ infections per se require hospitalization and many cases acquired during hospitalization could have been dealt with in an ambulatory setting.

Our study has strengths and some limitations. As a strength, case ascertainment was comprehensive with two independent data sources and the fact that in-house antigen testing for rotavirus is standard care in children hospitalized with gastroenteritis in our institution. Further, the study period covered almost 4 years and therefore is likely to be representative.

As a limitation, no comparisons with RV negative episodes of gastroenteritis were performed. However, it is well known that these are less severe than RV gastroenteritis [23]. Further, as with any retrospective study design, data need to be interpreted with caution.

\section{Conclusion}

RV gastroenteritis causes a substantial burden for infants and young children and their families in our area. This population based data provide a basis for individual decisions regarding immunization against rotavirus and can guide pediatricians in order to promote $\mathrm{RV}$ vaccination in their patients, which has been recommended by a European expert group recently [34].

\section{References}

1. Albano F, Bruzzese E, Bella A et al (2007) Rotavirus and not age determines gastroenteritis in children: a hospital-based study. Eur J Pediatr 166:241-247. doi:10.1007/s00431-006-0237-6

2. Alcalde FJ, Bouza JM, Rubio AP et al (2008) Gastroenteritis by rotavirus in Spanish children. Analysis of the disease burden. Eur J Pediatr 167:549-555. doi:10.1007/s00431-007-0550-8

3. Berner R, Schuhmacher RF, Hameister S et al (1999) Occurrence and impact of community acquired and nosocomial rotavirus infections: a hospital-based study over 10 years. Acta Paediatr Suppl 426:48-52. doi:10.1111/j.1651-2227.1999.tb14326.x

4. Bernstein DI, Sack DA, Reisinger K et al (1999) Efficacy of a live attenuated human rotavirus vaccine $89-12$ in infants: a randomized placebo-controlled trial. Lancet 354:287-290. doi:10.1016/ S0140-6736(98)12106-2

5. Bevölkerung In: Bundesamt für Statistik (BFS), Herausgeber. Statistisches Jahrbuch der Schweiz, 2001-2004
6. Bucher B, Aebi C (2006) Population-based epidemiology of rotavirus hospitalisations in Switzerland. Swiss Med Wkly 136:726-731

7. Centers for disease control and prevention (1999) Intussusception among recipients for rotavirus vaccine: United States, 1998-1999. MMWR 48:577-581

8. Chang HG, Glass RI, Smith PF et al (2003) Disease burden and risk factors for hospitalizations associated with rotavirus infection among children in New York State, 1989 through 2000. Pediatr Infect Dis J 22:808-814. doi:10.1097/01.inf.0000086404.31634.04

9. Diez-Domingo J, Martin IO, Sanz AB et al (2006) Rotavirus gastroentritis among children under five years of age in Valencia, Spain. Pediatr Infect Dis J 25:455-457. doi:10.1097/01.inf.0000 217378.30444.21

10. Ehlken B, Laubereau B, Karmaus W et al (2002) Prospective population-based study on rotavirus disease in Germany. Acta Paediatr 91:769-775. doi:10.1080/08035250213227

11. Floret D, Lina B, Pinchinat S et al (2006) Epidemiology and burden of rotavirus diarrhea in day care centers in Lyon, France. Eur J Pediatr 165:905-906. doi:10.1007/s00431-006-0187-z

12. Frühwirth M, Heininger U, Ehlken B et al (2001) International variation in disease burden of rotavirus gastroenteritis in children with community- and nosocomially acquired infection. Pediatr Infect Dis J 20:784-791. doi:10.1097/00006454-20010800000013

13. Glass RI, Kilgore PE, Holman RC et al (1996) The epidemiology of rotavirus diarrhea in the United States: surveillance and estimates of disease burden. J Infect Dis 174(Suppl):S5-S11

14. Huppertz HI, Forster J, Heininger U et al (2008) The parental appraisal of the morbidity of diarrhea in infants and toddlers (PAMODI) survey. Clin Pediatr (Phila) 47:363-371. doi:10.1177/ 0009922807310933

15. Joensuu J, Koskenniemi E, Pang XL et al (1997) A randomised, double blind, placebo controlled trial of rhesus-human reassortant rotavirus vaccine for prevention of severe rotavirus gastroenteritis. Lancet 350:1205-1209. doi:10.1016/S0140-6736(97)05118-0

16. Johansen K, Bennet R, Bondesson K et al (1999) Incidence and estimates of disease burden of rotavirus in Sweden. Acta Paediatr Suppl 88:20-23. doi:10.1111/j.1651-2227.1999.tb14321.x

17. Kapikian AZ (1996) Overview of viral gastroenteritis. Arch Virol Suppl 12:7-19

18. Koopmans M, Van Asperen I (1999) Epidemiology of rotavirus infections in the Netherlands. Acta Paediatr Suppl 88:31-37. doi:10.1111/j.1651-2227.1999.tb14323.x

19. Laubereau B, Gateau S, Ehlken B et al (1999) RotavirusGastroenteritis im Säuglings- und Kleinkindesalter. Ergebnisse einer prospektiven Erfassung in den Regionen Genf und Basel 1997/1998 (RoMoS). Schweiz Med Wochenschr 129:1822-1830

20. Lynch M, O'Halloran F, Whyte D et al (2001) Rotavirus in Ireland: national estimates of disease burden, 1997 to 1998 . Pediatr Infect Dis J 20:693-698. doi:10.1097/00006454200107000-00010

21. Matson DO, Estes MK (1990) Impact of rotavirus infection at a large pediatric hospital. J Infect Dis 162:598-604

22. Mrukowicz JZ, Krobicka B, Duplaga M et al (1999) Epidemiology and impact of rotavius diarrhea in Poland. Acta Paediatr Suppl 88:53-60. doi:10.1111/j.1651-2227.1999.tb14327.x

23. Parashar UD, Hummelmann EG, Bresee JS et al (2003) Global illness and deaths caused by rotavirus disease in children. Emerg Infect Dis 9:565-572

24. Raes M, Aerssens Alliet P et al (2008) Rotavirus gastroenteritis: epidemiological data from a regional hospital in Belgium. Eur $\mathrm{J}$ Pediatr 167:71-73. doi:10.1007/s00431-007-0428-9

25. Rennels MB, Glass RI, Dennehy PH et al (1996) Safety and efficacy of high-dose rhesus-human reassortant rotavirus vaccines: report of the national multicenter trial. Pediatrics 97:7-13 
26. Ruggeri FM, Declich S (1999) Rotavirus infection among children with diarrhea in Italy. Acta Paediatr Suppl 426:66-71. doi:10.1111/j.1651-2227.1999.tb14329.x

27. Ruuska T, Vesikari T (1990) Rotavirus disease in Finnish children: use of numerical scores for clinical severity of diarrheael episodes. Scand J Infect Dis 22:259-267. doi:10.3109/0036554 9009027046

28. Ryan MJ, Ramsay M, Brown D et al (1996) Hospital admissions attributable to Rotavirus infection in England and Wales. J Infect Dis 174(Suppl 1):S12-S18

29. Tucker AW, Haddix AC, Bresee JS et al (1998) Cost-effectiveness analysis of rotavirus immunization programmed for the United States. JAMA 279:1371-1376. doi:10.1001/jama.279.17.1371

30. Velazquez FR, Matson DO, Guerrero ML et al (2000) Serum antibody as a marker of protection against natural rotavirus infection and disease. J Infect Dis 182:1602-1609. doi:10.1086/ 317619
31. Vesikari T, Clark HF, Offit PA et al (1996) The development of a multivalent bovine rotavirus (strain WC3) reassortant vaccine for infants. J Infect Dis 174(Suppl 1):S73-S80

32. Vesikari T, Matson DO, Dennehy P et al (2006) Safety and efficacy of a pentavalent human-bovine (WC3) reassortant rotavirus vaccine. $\mathrm{N}$ Engl J Med 354:23-33. doi:10.1056/ NEJMoa052664

33. Vesikari T, Rautanen T, Von Bonsdorff CH (1999) Rotavirus gastroenteritis in Finland: burden of disease and epidemiologic features. Acta Paediatr Suppl 426:24-30. doi:10.1111/j.16512227.1999.tb14322.x

34. Vesikari T, Van Damme P, Giaquinto C et al (2008) European Society for Paediatric Infectious Diseases/European Society for Paediatric Gastroenterology, Hepatology, and Nutrition evidencebased recommendations for rotavirus vaccination in Europe: executive summary. J Pediatr Gastroenterol Nutr 46:615-618. doi:10.1097/01.mpg.0000319063.86281.40 